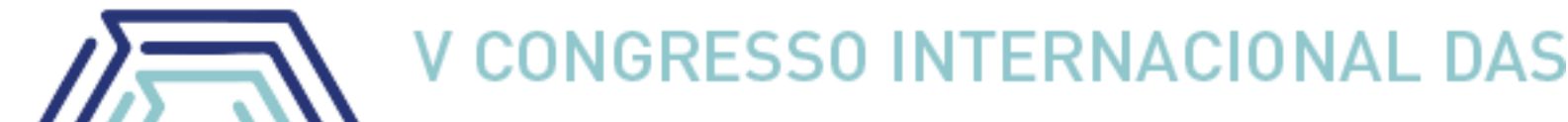 LICENCIATURAS COINTER - PDVL 2018
}

\section{O USO DE MODELOS DIDÁTICOS NO ENSINO E APRENDIZAGEM DO SISTEMA URINÁRIO}

\section{THE USE OF DIDACTIC MODELS IN TEACHING AND LEARNING OF THE URINARY SYSTEM}

\author{
Apresentação: Pôster
}

\begin{abstract}
Tamyres Lopes Rios ${ }^{1}$; Tiago Rodrigues da Silva ${ }^{2}$; Bruna Rodrigues da Silva ${ }^{3}$; Evandro Bacelar Costa ${ }^{4}$ Marlúcia da Silva Bezerra Lacerda ${ }^{5}$
\end{abstract}

\section{DOI: https://doi.org/10.31692/2358-9728.VCOINTERPDVL.2018.00231}

\section{Introdução}

O ensino e aprendizagem de Anatomia Humana na educação básica apresentam dificuldades, principalmente em razão da linguagem técnica complexa. Conforme, Krasilchik (2008) nas aulas de Anatomia Humana há uma ênfase na nomenclatura em lugar do destaque analítico das estruturas e processos biológicos. De modo geral, a prática docente é centralizada apenas em aulas teóricas e expositivas com auxílio de livros didáticos que trazem imagens estáticas e fragmentadas do corpo humano.

Dado isso, as compreensões de Anatomia Humana vistas na educação básica são limitadas às descrições audiovisuais, uma vez que as escolas não dispõem de laboratórios equipados para aulas práticas dos sistemas corpóreos humanos. Nesse sentido, os modelos didáticos ganham seu espaço nas aulas práticas, uma vez que permitem melhores visualizações dos órgãos quando comparados com a utilização apenas de livros didáticos (DUSSO et al., 2013; MOURTHÉ FILHO et al., 2016). Com isso, a modelização didática emergiu da necessidade de empregá-la para facilitar a aprendizagem dos alunos no ensino de Ciências (ASTOLFI; DEVELAY, 2012).

\footnotetext{
1 Graduanda em Licenciatura em Ciências Biológicas pelo IFPI, campus Teresina Central, e-mail: tamyresrios1@hotmail.com

${ }^{2}$ Especializando em Ensino de Ciências, IFMA, campus Timon, e-mail: thiago2581@hotmail.com

3 Graduanda em Licenciatura em Ciências Biológicas pelo IFPI, campus Teresina Central, e-mail: brunarodrigues.bs@hotmail.com

${ }^{4}$ Especializando em Ensino de Ciências, IFMA, campus Timon, e-mail: evandrobc1@hotmail.com

${ }^{5}$ Professora, IFPI, Campus Teresina Central, e-mail: marlucia.lacerda@ifpi.edu.br
} 
Nessa perspectiva, o presente estudo busca responder a seguinte problemática: Quais as contribuições do uso de modelos didáticos para o aprendizado dos conteúdos do sistema urinário em uma turma de $8^{\circ}$ ano do ensino fundamental de uma escola pública em Timon, Maranhão? Para tal, parte-se da hipótese que a construção de modelos didáticos torna os alunos aptos a compreender e reconhecer a morfologia e fisiologia do aparelho urinário.

Desse modo, objetivo do trabalho foi analisar o desenvolvimento da modelização didática aplicada no ensino e aprendizagem do sistema urinário aos alunos no $8^{\circ}$ ano do Ensino Fundamental, em uma escola pública municipal de Timon, MA.

\section{Fundamentação Teórica}

Os modelos podem ser conceituados como processos que representam determinados eventos, por meio de imagens e analogias, cuja finalidade é ajudar os alunos e cientistas na visualização e compreensão de algum conteúdo, e de modelagem como a construção dos modelos (DUSSO et al., 2013). Assim, a atividade de modelos e modelização no ensino de Biologia indicam que a sua utilização tem por finalidade promover meios para os alunos compreenderem os modelos científicos, que expressam o consenso da comunidade acadêmica sobre determinados fenômenos (ASTOLFI; DEVELAY, 2012).

Os modelos pedagógicos são elaborados e aceitos como processos para uma aprendizagem no ensino de Ciências/Biologia e estão relacionados, principalmente, com as teorias da aprendizagem. (DUSSO et al., 2013). Logo, o uso de modelos didáticos é um dos métodos alternativos para trabalhar o ensino de Anatomia Humana nas aulas de Ciências e Biologia (ALEXANDRE et al., 2017).

Sendo, portanto, instrumentos pedagógicos capazes de explorar explicações dos processos biólogos por parte dos alunos, e que garantem a construção de conhecimentos. Com efeito, os professores de Ciências/Biologia passaram a fazer usos de maquetes e esquemas com o objetivo de solidificar suas explicações sobre os conteúdos. Nesse sentido, torna-se mais propício estabelecer conexões e compreensões dos eventos naturais por parte dos estudantes (ORLANDO et al., 2009).

\section{Metodologia}

O estudo foi de natureza básica com uma abordagem quali-quantitativa e descritiva quanto aos objetivos, caracterizando-se como uma pesquisa-ação (GIL, 2010). A sequência 
didática foi realizada nos meses de agosto e início de setembro de 2018 com uma turma de 30 alunos do $8^{\circ}$ ano do Ensino Fundamental de uma escola pública, a Unidade Escolar Luiz Miguel Budaruiche, localizada na cidade de Timon, MA.

A prática pedagógica foi aplicada em duas etapas. A primeira com 04 aulas duplas semanais de 50 minutos (nos dias 01 e 08 de agosto) sobre os aspectos teóricos da morfologia e fisiologia do sistema urinário, leituras de textos acerca da saúde do sistema corpóreo supracitado e resolução de exercícios no quadro branco com apoio do livro didático dos alunos.

$\mathrm{Na}$ segunda etapa foi realizada a atividade de modelização didática na sala de aula. A construção dos modelos ocorreu pelos próprios alunos organizados em grupos - de três a quatro integrantes - com materiais de baixo custo, fácil obtenção, manuseio e disponibilizados pelo professor. Assim, na modelização didática os estudantes usaram folhas de E.V.A (etil vinil acetato), cola de isopor ou branca, tesouras e uma base de papelão nas dimensões de uma folha A4 (21,0 X 29,7 cm). No decorrer da confecção dos modelos, o professor realizou explicações sobre as funções e órgãos que compõem o sistema urinário e esclarecendo as eventuais dúvidas dos alunos. Além disso, ao final da produção dos modelos pelos grupos de alunos, o professor realizava um jogo de perguntas aos estudantes. Nesse caso, lançava uma pergunta referente aos conteúdos abordados nos modelos e selecionava um aluno para proferir a resposta, podendo haver a intervenção dos demais integrantes do grupo.

Desta forma, as respostas dos alunos durante as apresentações dos modelos construídos e as observações verificadas pelo professor em sala aula foram as técnicas utilizadas para coletar os dados e fazer a composição e triangulação dos resultados.

\section{Resultados e Discussão}

Na construção dos modelos didáticos verificou-se uma socialização dos conhecimentos entre os estudantes na medida em que se identificaram diálogos acerca do formato, tamanho e localização dos rins e vias urinárias. Com isso, tornou-se possível o professor notar a assimilação de alguns termos e significados que foram expressos nas aulas teóricas e dialogadas. Assim, as atividades de modelização são capazes de avivar o interesse dos alunos pelos conteúdos conceituais, promovendo o desenvolvimento da imaginação, reflexão e raciocínio. Adicionalmente durante a produção dos modelos didáticos, têm-se a oportunidade de o professor estabelecer maiores vínculos entre as aulas teóricas e a prática pedagógica de 
modelização, tornando o aluno um sujeito ativo e interativo nos processos de aprendizagem (DUSSO et al., 2013).

A produção dos modelos didáticos incentivou os alunos a uma reflexão e pesquisas no livro didático sobre a morfologia e fisiologia do sistema urinário. Na realização da modelização didática foram confeccionados 18 modelos, 09 representando o sistema urinário e os demais modelos pedagógicos da morfologia dos rins. Na Figura 1 é possível observar alguns exemplos dos trabalhos de modelagem didática feitos pelos alunos.

Figura 1: Modelos didáticos do sistema urinário e rins, construídos pelos alunos. Fonte: Própria

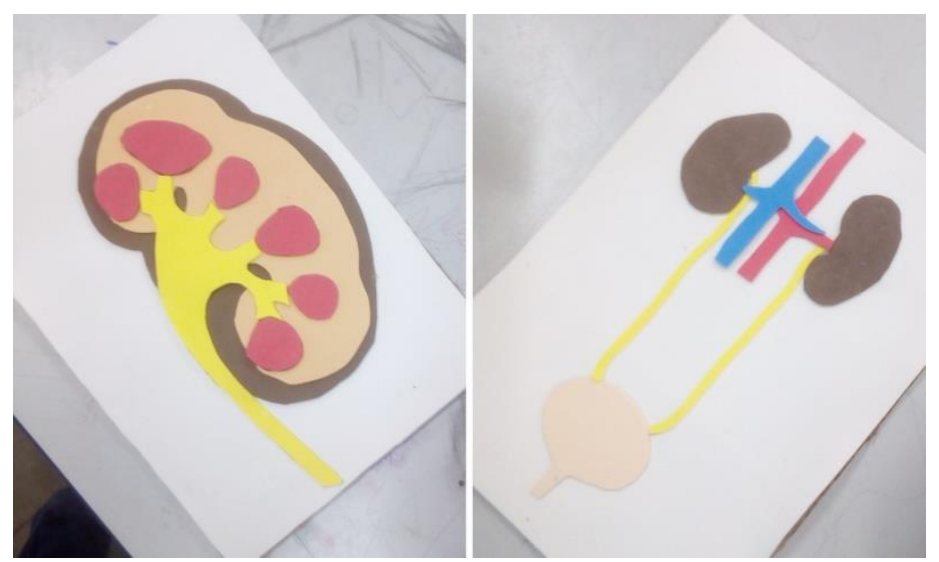

Pode-se observar que os estudantes na construção de seus modelos foram desenvolvendo uma melhor capacidade de estabelecer as relações entre os órgãos do sistema corpóreo supracitado e seus posicionamentos anatômicos. Tendo isso em vista, Krasilchik (2008) afirma que os modelos didáticos não podem ser aplicados, puramente, como uma ilustração da teoria vista em sala de aula. Por isso, a autora advoga que os alunos sejam participativos nos processos que colocam a modelização didática para facilitar a aprendizagem.

Desta forma, as confecções dos modelos pelos alunos efetuam um aprimoramento dos conhecimentos abordados nas aulas teóricas, bem como permitiu aos estudantes construir seus conceitos e significados acerca dos sistemas do corpo humano, ao invés de receberem as informações de forma passiva (ORLANDO et al., 2009; ALEXANDRE et al., 2017).

Diversos autores, tais como, Orlando et al. (2009), Dusso et al. (2013), Alexandre et al. (2017) quando abordam o uso de modelos didáticos na aprendizagem, argumentam que os mesmos provocam melhorias na fixação dos conteúdos científicos nas estruturas cognitivas dos alunos, pois ocorre o aumento da propensão dos estudantes relacionarem o material produzido com as funções biológicas e órgãos que estão sendo representados.

Para Mourthé Filho et al. (2016), há indícios de melhorias nos processos de ensino e aprendizagem de Anatomia Humana quando os alunos apresentam capacidades de associar as 
nomenclaturas dos órgãos e estruturas com as respectivas funções. Nesse sentido, os modelos didáticos foram ferramentas capazes de compor um melhor entendimento da fisiologia dos órgãos, uma vez que o contato físico com a modelização permite uma visualização das estruturas, e por consequência torna os conceitos menos abstratos. Desse modo, a utilização de modelos didáticos nas aulas reforçou os conteúdos de fisiologia vistos nas aulas teóricas e expositivas, ou seja, provocaram resignificações aos termos e conceitos apresentados nas aulas tradicionais.

\section{Conclusões}

Os resultados evidenciam que a atividade de modelização didática teve uma boa aceitação pelos alunos, permitindo-os revisar os conteúdos ministrados nas aulas teóricas e expositivas de forma palpável. Além disso, a construção dos modelos didáticos mostrou ser uma atividade que permite colocar os alunos em processos de socialização de conhecimentos. Desse modo, torna-se viável concluir que após a construção dos modelos didáticos se obteve melhores concepções dos conteúdos científicos vistos durante as aulas semanais de Ciências.

\section{Referências}

ASTOLFI, J. P.; DEVELAY, M. A didática das ciências. Magda Sento Sé Fonseca [tradução]. 16 ed. Campinas/SP: Papirus, 2012.

ALEXANDRE, J. S.; MENDONÇA, V. A.; MENDONÇA, M. C. F. B. Construção de modelos didáticos para o ensino de ciências: sistema urinário. Experiências no Ensino de Ciências, v, 12 , n. 7, p. 100-107, 2017

DUSSO, L; et al. Modelização: uma possibilidade didática no ensino de biologia. Revista Ensaio, Belo Horizonte, v. 15, n. 2, maio-ago., p. 29-44, 2013.

GIL, A. C. Como elaborar projetos de pesquisa. 5. ed. São Paulo: Altas, 2010.

KRASILCHIK, M. Práticas no ensino de biologia. 4. ed. São Paulo: EDUSP, 2008.

MOURTHÉ FILHO, A,; et al. Refletindo o ensino da anatomia humana. Enfermagem Revista, Belo Horizonte, v. 19, n. 2, p. 169-175, 2016

ORLANDO, T. C.; et al. Planejamento, montagem e aplicação de modelos didáticos para uma abordagem de biologia celular e molecular no ensino médio por graduandos de ciências biológicas. Revista Brasileira de Ensino de Bioquímica e Biologia Molecular, n. 1, 2009. 